\title{
Agile organization: Introducing self-managed teams
}

\author{
Lucia Kohnová $^{1}$ and Nikola Salajová ${ }^{2}$ \\ ${ }^{1}$ Faculty of management, Comenius University, Bratislava, Slovakia \\ ${ }^{2}$ Faculty of management, Comenius University, Bratislava, Slovakia \\ lucia.kohnovalfm.uniba.sk, nikola.salajovalfm.uniba.sk
}

\begin{abstract}
The current changes in the business environment, which are accompanied by strong technological developments, have led to the acceleration of change and the constant need to adapt to the market. At present, companies have to cope with a number of changes, both in terms of the implementation of new technologies, changes in the content and scope of work of employees and in the overall approach to management. An agile approach to leadership and the creation of self-managed teams is a trend that has gained in popularity in recent years. Many researches already point to the fact that agile teams increase the flexibility of the organization and contribute to higher employee satisfaction with work. However, the transition from the classic rigid approach to employee management to agile is challenging and many organizations approach it only cautiously. The main goal of the study was to analyze the level of implementation of self-organized teams and the level of employee participation in planning their work tasks in Slovak companies and to examine the differences based on the size of the organization. When collecting data, we focused on 50 companies while obtaining information from the HR department on employee management. We found out that up to $74 \%$ of Slovak companies do not plan to implement agile principles within their teams. An interesting fact is that more SMEs than large companies are interested in this trend. Survey has also shown that only $8 \%$ organizations enable employees to plan tasks independently. Especially in large companies, scheduling tasks with a supervisor is very important. Slovakia, as an industrial country, is significantly affected by technological changes, but the adaptation of technologies without appropriate changes in management may not lead to the expected results in the context of future competitiveness.
\end{abstract}

Keywords: Agile management, self-managed teams, self-organization.

\section{$1 \quad$ Introduction}

In recent years, agile methods have become increasingly popular in the world. Agile methods have been incorporated into their philosophies not only by multinational corporations, but also by universities, telecommunications, banks, the automotive industry and many small and medium-sized companies [1]. Strategic agility is the background for organizations that want to successfully face changes in the environment. Organizations that fail to adapt will not survive. An agile organization must be resilient, able to 
anticipate, initiate and seize opportunities. For these organizations is important the relationship with employees and how they feel identified with organizational mission [2]. As a result, there is a growing demand for effective human resource management in agile environments [3]. Important factors in employee agility are adaptive behavior, which means the employee's ability to respond to ongoing changes in the environment, and proactive behavior, which is the employee's ability to create new opportunities [4]. Sherehiy and Karowowski (2014) summarized the five dimensions of work organization that have a significant impact on employee performance. These dimensions are: a) work requirements: the effort the employee needs to make to perform the work; b) control / autonomy of work: the degree of independence that the employee has at work and the autonomy of deciding how to perform the work; c) work complexity: the degree to which the work is complex; d) diversity of skills: what skills and abilities of employee the work requires; e) unpredictability of work: to what scale work is unpredictable and represents uncertainty for the employee [5]. Regarding to employees, the topic of agile teams is an increasingly discussed topic today. The fact that cooperating teams achieve better results than groups of individually working individuals has been known for a long time [1]. If organizations decide to implement agile teams, they must accept that until individuals in the teams learn a new way of leading the team, their results will be achieved at a slower pace [6].

\section{$2 \quad$ Literature review}

Unlike a traditional team, an agile team is able to self-organization, arranged in a flat hierarchy, capable of reacting quickly to changes in the environment. Team members work closely together, meet, communicate to explore of issues of the best way. Other assumptions for a successful agile team are motivating individuals, fulfilling a common vision of the project, continuous learning to be able to adapt to changing needs and environments. In common meetings, each team member is expected to engage in discussion and provide feedback [7]. Šochová \& Kunce (2014) present that the condition for the creation of a self-organized team is a common goal and vision. Team members need to know the customer well and know how they want to use the product. Another important element is the trust between team members, the customer and the whole company [1]. Cockburn and Highsmith (2001) state that an agile team is characterized by self-organization and cohesive cooperation within the organization and beyond. Selforganizing teams are able to work in different variations to solve ad-hoc problems [8]. Guzzo \& Dickson (1996) refer to self-organizing teams as self-managing teams, where members perform interconnected tasks. Team members are responsible for their work, they can plan, divide tasks and make decisions [9]. On the other hand, middle managers are not protagonists of self-organized teams, as they lose authority and, in some cases - shorten the hierarchy - they can lose their position [10]. According to Chow and Cao (2007), an effective agile team consists of members who dispose of special skills, are motivated, well trained, managers have agile knowledge and apply an adaptive leadership style [11]. Hoda et al. (2013) define self-organizing teams as teams with a high degree of autonomy. Members are able to organize themselves in performing tasks [12]. 
Autonomous agile teams usually maintain a higher emotional relation to the organization, leading to greater commitment, motivation to perform, and a desire for responsibility. As a result, employees pay more attention to their work, which leads to greater creativity, higher productivity and quality of services [13,14]. Accepting agility causes a visible change in productivity, efficiency and brings satisfaction to team members. Agility also reduces team members' time required for routine tasks, and team members can gain a higher ranking in the team [15]. One of the important benefits for employees to become a member of an agile team can be strengthening their position in the organization [16]. Managers of Deloitte company (2010) report the following benefits of a self-organized team: increased productivity, greater motivation, clear responsibility and reliability, employee development and growth, better team cohesion [17]. However, implementing self-organizing teams is challenging. Organizations often think that employees can just move from traditional hierarchically organized work to a self-organized type of work without education and any training. Not all employees are ready to work without directions from a superior and are not ready to take responsibility. Therefore, the provision of training and coaching is very important when moving to selforganized teams [10].

Agile teams can work in both physical and virtual environments, as members can be distributed in different geographic locations [18]. The essential elements of the success of a virtual agile team are the right structure, the team's ability to constantly improve, be self-managing, make collective decisions and apply shared leadership. Forming team like this is time consuming and requires professional coaching [19]. One of the conditions for the functioning of a successful agile virtual team is the selection of a adequate technology. The organization should pay attention to technologies that achieve highspeed connectivity, dispose of newer PCs with licensed software, and high-quality audiovisual conferencing tools [20]. On the other hand, there are also negatives that occur in agile team. Whithworth \& Biddle (2007) identify several negative aspects associated with agile teams: a) stress or exhaustion of team members throughout the day where they were too active; $b$ ) 'burnout syndrome' caused by constant contact with the same people every day or performing the same project activities; $c$ ) the inability of individuals to fit into an agile team; d) difficulties and stress of individuals in transitioning to an agile team culture [21].

Self-organizing teams do not form and prosper in isolation. They depend on the support of top management and the involvement of customers in the process [22]. Goodman et al. (1988) identified in self-organizing teams as the most important attributes: a) employees responsible for product development with related tasks; $b$ ) the autonomy of the employees in the dividing of tasks, the work schedule and the way the work is done; c) mutual communication [23].

Self-organizing teams face permanently new challenges in performing day-to-day project management activities [24]. One of the challenges of agility is to effectively measure team performance. However, agile teams use their own metrics that emerge from identified needs. Commonly used metrics are customer satisfaction, delivery ontime, business value, quality, productivity, predictability [25]. In an agile team, members should act initiative not only within the team, but also beyond its borders, thus in cooperation with the customer. The agile team should be made up of individuals who 
are constantly improving their working methods and are able to accept change and feedback in all areas of work [26, 27]. Barker (1993) states in his study that members of self-managing teams achieved a lower rate of absenteeism because they set strict norms for arrival in advance [28].

Hoda et al. (2010) presented in their research of effective way of organizing autonomy teams in an agile environment. They state that team members should assume 6 tasks to facilitate work organization [22]:

1. Mentor - provides initial leadership, supports agile methods in the team and ensures their observance

2. Coordinator - communicates with customers about their requirements and possible changes

3. Translator - transforms the language used by customers into team terminology in order to improve communication

4. Champion - receives the support of top management in context of the formation of pilot teams able to self-organizing

5. Promoter - ensures the involvement of customers in the process of work of an agile team, thus creating cooperation between members and customers

6. Terminator - eliminates members who are unable to adapt to an agile approach, thus blocking productivity

\subsection{Barriers of agile teams}

The performance of an agile team depends not only on the team's ability to manage and perform work, but also on the organizational context provided by the organization's management. Stray et al. (2018) define barriers that can restrain the performance of agile teams [29]:

a) Objectives are not clear and common: this barrier occurs when members are more concerned with examining what will be achieved and, in the result, team activities are not coordinated.

b) Lack of trust: unless there is trust in the team, members are not committed to achieving the goals. If a manager constantly monitors team members, there is a lack of trust between them, which can reduce the level of responsibility of members in performing tasks.

c) High dependence on others: if a team needs to get acceptance for outputs from managers, stakeholders, it loses the power of independent decision-making

d) Limited coaching and organizational support: teams often do not have adequate resources and have difficulties with sustainability. Managers are not trained to lead an autonomous team.

e) Diversity in standards: Standards are informal rules that guide a team and the behavior of team members. These standards often do not support the strategic thinking that is necessary in agile teams. 


\section{$3 \quad$ Materials and methods}

The main goal of the study was to analyze the level of implementation of self-organized teams and the level of employee participation in planning their work tasks in Slovak companies and to examine the differences based on the size of the organization. The research data were collected through a questionnaire distributed to $50 \mathrm{HR}$ specialists. The questions used in questionnaire were: "Is there a discussion in your company about self-management, self-managed teams?" with possible options:

- No, I have not met with the term yet;

- No, but we have noticed this trend;

- There is a talk of this, but the company does not plan any changes;

- Yes, there is an interest in establishing self - management, self - managed teams;

- Yes, the company is already implementing (has established) self-managed teams.

and "To what extent does the employee in your company participate in planning their work tasks?" with possible options:

- Employee plans his tasks all by himself;

- Employee plans his own tasks and consults with her superior;

- The work tasks of the employee are planned by the superior, he also consults with the employee;

- The work tasks of the employee are planned only by the superior.

The survey was part of a research project that collected data in February 2020. In the research, companies were analyzed according to the size of the organization. The Chi square test was used in the analysis to reveal the significance of the differences, the significance was tested at the level of $\mathrm{p}=0.05$.

\section{$4 \quad$ Results}

In this research paper we have analyzed 50 Slovak companies and their attitude towards self-managed, agile teams. From the sample companies, $14 \%$ are already introducing (or have introduced) self-managed teams. However, 74\% do not plan to introduce this change in organizing teams. While most of the companies have at least met with the term, $22 \%$ of the companies have never heard the term. 
Yes, the company is already implementing (has established) self-managed teams

Yes, there is an interest in establishing self - management, self - managed teams

There is a talk of this, but the company does not plan any changes

No, but we have noticed this trend

No, I have not met with the term yet

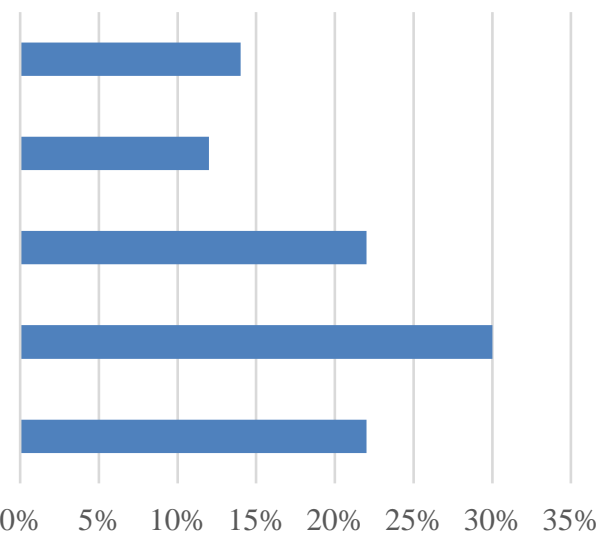

Fig. 1. Percentage comparison of Slovak companies in approach to agile management of teams.

When comparing large companies to SMEs in our sample, we observed that SMEs in were not in the process of introducing self-managed teams, however $29 \%$ of SMEs are interested in introducing this agile approach, significantly more than large companies (Chi square $=5.06, \mathrm{p}$ value $=0.02)$. Further, $43 \%$ of SMEs talk about agile approach, while the do not plan any specific changes in the business. Interestingly more large companies in our sample have not met the term, or just noticed this trend without any plans of introducing it to the company.

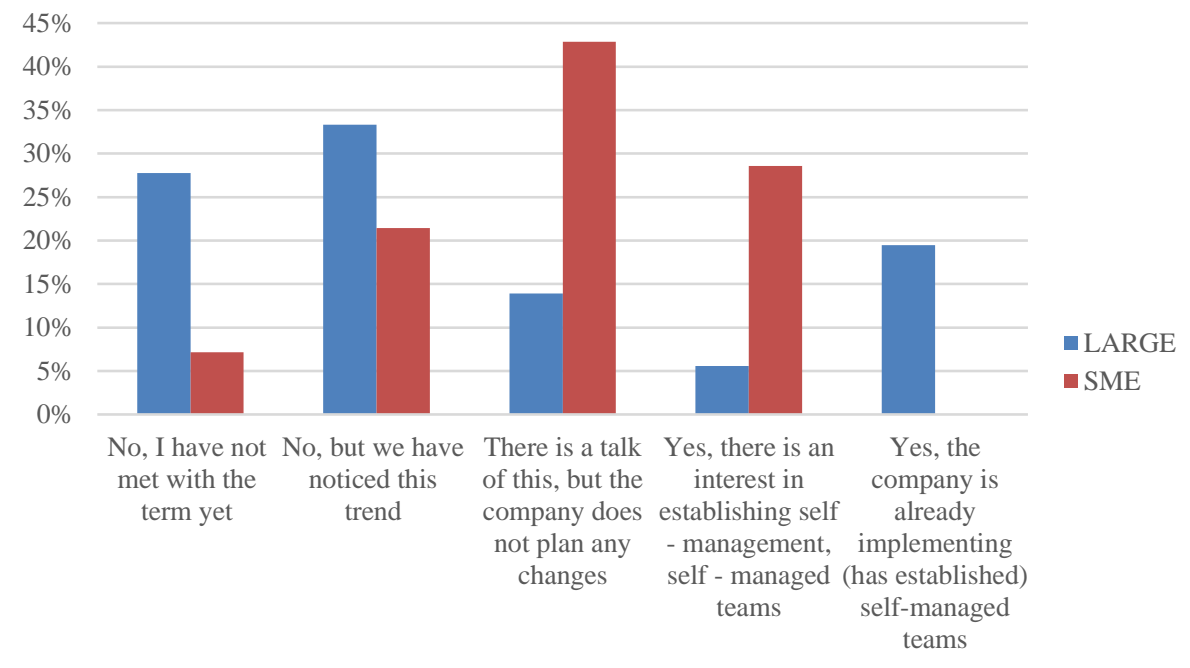

Fig. 2. Percentage comparison of large and SME Slovak companies in approach to agile management of teams. 
To compare the plans with actual way of managing employees, we have looked at to which extent companies involve employees in the process of organizing their work. In the analyzed sample, $86 \%$ of companies cooperate with employees in planning their work content. $38 \%$ of companies realize the approach where superior plans the work for employee and consults with him, $48 \%$ realize approach where employee plans their own work and consults with the superior. Only $8 \%$ of companies let the employee to plan their work alone. Similarly, $8 \%$ of companies let only the superior to plan the work for employee.

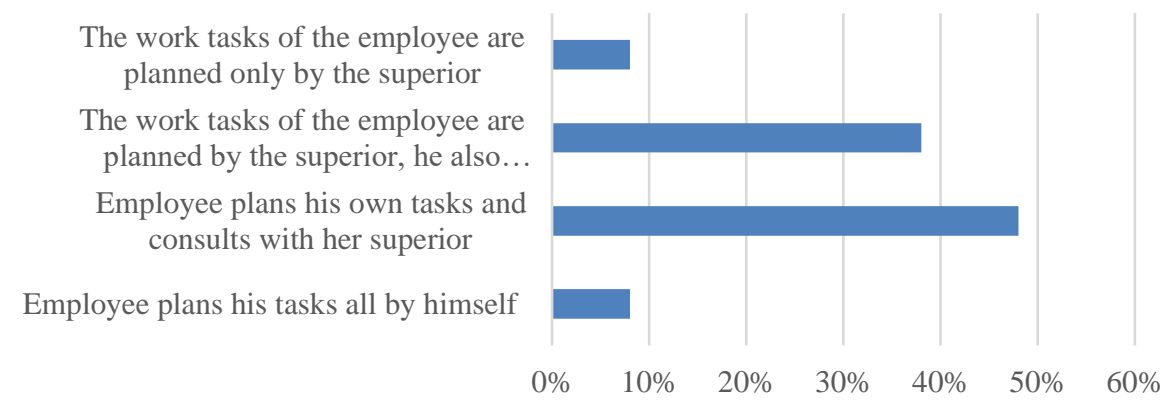

Fig. 3. Percentage comparison of Slovak companies in planning employee work tasks.

When comparing large companies and SMEs, $21 \%$ of SMEs let the employees to plan their work by themselves, while this difference was found to be statistically significant at $\mathrm{p}<0,05$ (Chi-square $=6.98, \mathrm{p}$ value $=0.01)$. Further $64 \%$ of SMEs in our sample let the employee plan the work while consulting with the superior. For large companies in this sample, the role of superior in planning the employee's work is more significant.

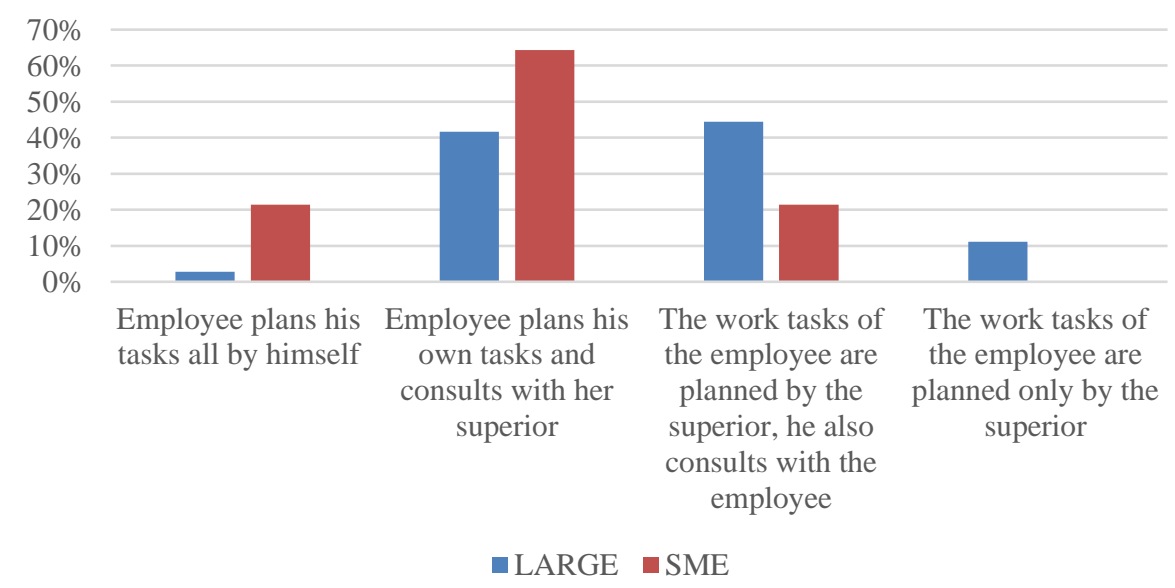

Fig. 4. Percentage comparison of large and SME Slovak companies in planning employee work tasks. 


\section{$5 \quad$ Discussion and conclusion}

In today's world of disruption, agility for organizations should not be an option, but a matter of course. For the success of organization, it is not enough to "do agile", but "be agile" is needed, which means that it is necessary to implement an agile approach, especially in the whole culture of organization. It is also important to note that agility is a commitment to provide added value to the customer more quickly and to be able to adapt more quickly to changing conditions [30]. In addition, if an organization does not have sufficiently qualified employees, able to work in self-organized teams, this can be a barrier to the development of agile adoption [15]. The survey identified findings based on the introduction of self-organized teams in Slovak companies. Although the introduction of agile teams is essential to support agile principles in the organization, up to $74 \%$ of Slovak companies do not plan to implement this change within their teams. An interesting fact is that more SMEs than large companies are interested in this trend, which could be understood in the context of power distance and the number of employees. Many SMEs can seem to be more agile, while company management is often very close to the self-managed team. Survey has also shown that up to $86 \%$ of Slovak companies collaborate with employees to plan their tasks. Only $8 \%$ organizations enable employees to plan tasks independently. The Chi square test found that especially in large companies, scheduling tasks with a supervisor is very important.

Based on our research, we can review that most of the surveyed Slovak companies are not interested in introducing agile principles into their teams. However, companies should reflect on this agile trend, as, as Deloitte (2018) points out, by introducing agile techniques, companies can increase their chances of keeping employees. Self-organized teams work autonomously, and they are empowered to decide on many issues, it can be more attractive for members because they develop their potential [17]. Moreover, the emergence of agile teams increases the importance of trust between team members, as members are free to develop the processes they prioritize and set goals they consider as appropriate. Team members who work together and trust each other are essential to the success of an agile organization. [31].

\section{Acknowledgements}

This research was supported and funded by APVV-17-0656 titled Transformation of Paradigm in Management of Organizations in the Context of Industry 4.0.

\section{References}

1. Šochová, Z., Kunce, E.: Agilní metody rrízení projektů. $1^{\text {st }}$ ed. Computer Press, Brno (2014).

2. Holbeche, L.: The Agile Organization. How to build an innovative, sustainable and resilient business. $1^{\text {st }}$ ed. Kogan Page Limited, London, UK (2015).

3. Jankelová, N., Joniaková, Z., Blštáková J., Némethová, I. Readiness of human resource departments of agricultural enterprises for implementation of the new roles of human resource professionals. Czech academy of agricultural sciences, 63 (10), 461-470 (2017).

4. Doeze Jager-Van Vliet, S. B., Born, M., Molen, H. T.: Using a portfolio-based process to develop agility among employees. Human Resource Development Quarterly, 1-22 (2019). 
5. Sherehiy, B., Karwowski, W.: The relationship between work organization and workforce agility in small manufacturing enterprises. International Journal of Industrial Ergonomics 44, 466-473 (2014).

6. Spiegler, S. V., Heinecke, Ch., Wagner, S.: Leadership Gap in Agile Teams: How Teams and Scrum Masters Mature. LNBIP 355, 37-52 (2019).

7. Smith, R.: Adopting 'Agile Leadership' in The Police Service. Scottish Institute for Policing Research, School of Social Sciences, University of Dundee, Dundee DD1 4HN (2008).

8. Cockburn, A., Highsmith, J.: Agile software development: The people factor. Computer 34(11), 131-133 (2001).

9. Guzzo, R. A., Dickson, M. W.: Teams in Organizations: Recent Research on Performance and Effectiveness. Annual Review of Psychology 47, 307-338 (1996).

10. Ivetic, P.: Holding the House of Cards Together: Possible Pitfalls with Self-Organizing Teams in Organizations. Project: Self-Organizing Teams in Organizations, 51-57. (2018).

11. Chow, T., Cao, D.-B.: A survey of critical success factors in agile software projects. The Journal of Systems and Software 81, 961-971 (2007).

12. Hoda, R., Noble, J., Marshall, S.: Self-organizing roles on agile software development teams. IEEE Transactions on Software Engineering, 39(3), 422-444 (2013).

13. Moe, N. B., Dingsøyr, T., Dybå, T.: Understanding Self-Organizing Teams in Agile Software Development. Conference: Software Engineering, ASWEC. 19th Australian Conference on Software Engineering (2008).

14. Stachová, K., Stacho, Z., Blštáková, J. - Hlatká, M., Kapustina, L.M. Motivation of Employees for Creativity as a Form of Support to Manage Innovation Processes in Transportation-Logistics Companies. International Journal of Maritime Science \& Technology, 65(4), 180-186 (2018).

15. KPMG Homepage, https://assets.kpmg/content/dam/kpmg/in/pdf/2017/10/Qualityinagileteams.pdf, last accessed 2020/06/14.

16. Moreira, M.: Being Agile: Your Roadmap to Successful Adoption of Agile. $1^{\text {st }}$ ed. Apress (2013).

17. Deloitte Development LLC Homepage, https://www2.deloitte.com/content/dam/Deloitte/ie/Documents/Technology/methods_in_systems_integration.pdf, last accessed 2020/06/15.

18. Alkema, P.: A Sentiment Scale For Agile Team Environments in Large Organizations: A Grounded Theory. University of the Witwatersrand (2020).

19. Moe, N. B., Dybå, T., Cruzes, D., Engebretsen, E.: Coaching a Global Virtual Team. 10th International Conference on Global Software Engineering (2015).

20. Amar, H., Haag, M: Exploring the Critical Success Factors of Virtual-Agile IT Projects: A Grounded Theory Study. International Journal of Innovation, Management and Technology 8(6), 427-434 (2017).

21. Whithworth, E., Biddle, R.: The Social Nature of Agile Teams. IEEE Explore, Washington, DC, USA (2007).

22. Hoda, R., Noble, J., Marshall, S.: Organizing self-organizing teams. International Conference on Software Engineering. Cape Town, South Africa (2010).

23. Goodman, P. S., Devadas, R., Hughson, T. L.: Groups and productivity: Analyzing the effectiveness of self-managing teams. Productivity in organizations, 295-325 (1988).

24. Hoda, R., Murugesan, L. K.: Multi_level Agile Project Management Challenges: A SelfOrganizing Team Perspective. The Journal of Systems and Software 117, 45-257 (2016).

25. ManagementSolutions, Homepage, https://www.managementsolutions.com/sites/default/files/publicaciones/eng/agile-organizations.pdf, last accessed 2020/06/15. 
26. Salin, N.: Supporting proactivity in agile project teams through self-organizing and shared leadership. LUT School of Business and Management (2017).

27. Lorincová, S., Hitka, M., Štarchoň, P. et al. Strategic Instrument for Sustainability of Human Resource Management in Small and Medium-Sized Enterprises Using Management Data. Sustainability, 10(10) (2018).

28. Barker, J. R.: Tightening the Iron Cage: Concertive Control in Self-Managing Teams. Administrative Science Quarterly 38(3), 408-437 (1993).

29. Stray, V., Moe, N. B., Hoda, R.: Autonomous agile teams: Challenges and future directions for research. 19th International Conference on Agile Software Development. In Proceedings of XP'18 Companion, Porto, Portugal (2018).

30. Capgemini consulting Homepage, https://www.capgemini.com/wp-content/uploads/2019/11/Report-\%E2\%80\%93-Agile-@-Scale-1.pdf, last accessed 2020/06/14.

31. McHugh O., Conboy K., Lang M.: Using Agile Practices to Build Trust in an Agile Team: A Case Study. In: Pokorny J. et al. (eds) Information Systems Development. Springer, New York, NY. (2011). 